\title{
Porosity Evaluation of Concrete Containing Supplementary Cementitious Materials for Durability Assessment through Volume of Permeable Voids and Water Immersion Conditions
}

\author{
Manish Kewalramani * and Ahmad Khartabil
}

check for updates

Citation: Kewalramani, M.; Khartabil, A. Porosity Evaluation of Concrete Containing Supplementary Cementitious Materials for Durability Assessment through Volume of Permeable Voids and Water Immersion Conditions. Buildings 2021, 11, 378. https://doi.org/ 10.3390 /buildings 11090378

Academic Editors: Haoxin Li,

Cong Ma and Tao Shi

Received: 19 July 2021

Accepted: 20 August 2021

Published: 25 August 2021

Publisher's Note: MDPI stays neutral with regard to jurisdictional claims in published maps and institutional affiliations.

Copyright: (C) 2021 by the authors Licensee MDPI, Basel, Switzerland. This article is an open access article distributed under the terms and conditions of the Creative Commons Attribution (CC BY) license (https:// creativecommons.org/licenses/by/ $4.0 /)$
Department of Civil Engineering, College of Engineering, Abu Dhabi University, Abu Dhabi 59911, United Arab Emirates; 1004786@students.adu.ac.ae

* Correspondence: manish.kewalramani@adu.ac.ae
Abstract: Concrete containing supplementary cementitious materials (SCMs) as partial replacement of ordinary Portland cement is regarded as green and durable concrete, with several advantages such as improved strength gain mechanism, resistance to degradation and extended service life of structure. Water absorption or porosity of concrete is directly related to the durability of concrete. In this present study, five concrete mixes involving three different SCMs are investigated for water absorption and rapid chloride penetration rating. A comparison between porosity values obtained using four standard testing methods, i.e., BS 1881-122, RILEM CPC 11.1, RILEM CPC 11.3, and ASTM C642 are presented for three different concrete mixes containing varied compositions and proportions of two SCMs. The testing method by RILEM CPC 11.3 includes distinctive sample preparation and is regarded as a stringent method to represent the degree of concrete porosity. Two additional concrete mixes with three SCMs are further investigated for their water absorption and immersion following the testing method by RILEM CPC 11.3. The impact of SCMs on concrete porosity is discussed. A linear correlation between porosity and rapid chloride penetration (RCP) ratings obtained as per ASTM C1202-19 on specimens of all investigated concrete mixes is proposed as a rapid approach to assess chloride penetration of concrete specimens containing SCMs.

Keywords: durability; water absorption; porosity; sustainable concrete; supplementary cementitious materials; rapid chloride penetration; water immersion

\section{Introduction}

Durability requirements of concrete mix have become a key parameter in civil engineering construction projects for evaluation of concrete performance towards serviceability, environmental deterioration, chemical attack and abrasion. Durability of concrete structures is primarily dependent on the design of mix, material used in the mix and issues related to construction besides degree of exposure. The durability of concrete ensures that the structure will achieve its targeted service life and will prove sustainable without major rectification, and hence it will be reliable, long lasting and cost-effective. Durability enhancing parameters are given due consideration in design standards and specifications. Concrete durability limits are also considered as a decisive criterion for concrete mix to be poured in structural elements in various regions including the United Arab Emirates. A very popular term 'Green Concrete' is used in the United Arab Emirates to refer to highly durable concrete that incorporates supplementary cementitious materials (SCMs). Green Concrete is enforced by the Dubai Municipality and Abu Dhabi Urban Planning Council to limit the carbon footprint of the construction industry and to increase the durability of the structures [1,2]. Replacing ordinary Portland cement (OPC) with SCMs such as Ground Granulated Blast furnace Slag (GGBS), Fly ash (FA) and Micro silica (MS) that have considerably lower carbon footprint is one of the prevalent practices used to meet sustainability constraints and the durability performance of concrete at the same time. 
Three standard tests in construction projects, i.e., 'Water Absorption', 'Water Permeability' and 'Rapid Chloride Penetration' in accordance with BS 1881-122, BS EN 12390-8, and ASTM C1202 conventionally assess the durability of concrete, respectively. Several researchers interpret results of these tests as means to evaluate the corrosion resistance of concrete or cementitious products in combination with a 90-day 'chloride ponding test' and 'corrosion macro cell test' [3]. Water absorption or porosity of concrete is an important parameter of assessment required for the design of reinforced concrete structural elements [4]. Malecot et al. [5] proposed an empirical triaxial failure criterion of concrete that takes into account the uniaxial strength, porosity and saturation ratio. The free water influence on concrete behavior depends on both the amount and nature of porosity. It was observed that the effect of capillary porosity is much higher compared to the effect of modifying the entrained air porosity. Accary et al. [6] proposed an experimental method aiming at measuring the pore pressure of free water into concrete samples under very high mean stress. In this study two types of deformable pressure sensors were designed and tested. The first one works in hydrostatic compression while the second one acts as a flexible membrane. Baroth et al. [7] provided experimental, analytical and numerical results predicting perforation of reinforced concrete slabs submitted to soft and hard impacts. The models of study accounted for free water saturation ratio and high triaxial stress. This paper provided analytical ballistic limit and residual velocities for both hard and soft impacts. Porosity and water absorption of other cementitious products such as bricks and mortar define the chemical stability of such cementitious products [8]. Generally, it is noticed that water absorption by immersion or porosity of concrete directly affect water permeability and rapid chloride penetration - the two important durability related parameters. The porosity of concrete has influences on properties in many aspects. Composition of concrete, casting in practice, maturing and hardening, cement reactions and risks at freezing are all influenced by porosity. It is for this reason that water absorption in a concrete member is related to the micro and nano structure matrix of the concrete, subsequently to the presence of voids and related characteristics. For example, the higher the volume of voids in hardened concrete, the easier and faster chloride ions diffuse through the concrete. Consequently, the lower the corrosion threshold of a concrete member, the quicker the occurrence of chloride-induced corrosion to the steel reinforcement [9]. As mentioned earlier, incorporating SCM is very beneficial for prolonging the service life of concrete structures, as these materials play a significant role in reducing the pores in the concrete matrix. Presence of SCM in concrete such as FA, GGBS, and MS individually or in combination reduce water absorption of concrete. GGBS was found to be more effective than MS in reducing the water absorption of concrete by immersion [10]. It is believed that steel slag deteriorates the early age hydration of cement. Zhuang and Wang [11] studied early age hydration kinetics and the evolution of the solid phase, aqueous species and microstructures in a cement-steel slag composite binder. The study found that steel slag slows the depletion of gypsum and reduces the formation of ettringite. It was also reported that steel slag significantly inhibits the precipitation of $\mathrm{CH}$ and C-S-H. Chen et al. [12] studied the effects of the chloride attack on the bonded system repaired by ultra-high performance concrete (UHPC). They investigated compressive strength, bonding and flexural behavior of UHPC with different fiber contents after different periods of chloride attack. It was found that the interfacial properties decrease after the chloride attack for the repaired system, and the UHPC bonded system demonstrated higher polarization resistance and free-corrosion potential. In order to study unified reactivity indices of different types of copper slag, Wang et al. [13] conducted an experimental study on ten copper slag samples. The results of the study showed that reactivity indices increased by reducing the water content, and a further increase is possible. Fe in copper slag plays an important role in stabilizing the heavy metals. However, reuse of copper slag as partial cement replacement possesses leaching risks of heavy metals. Bao et al. [14] utilized ferronickel slag (FNS) as the fine and coarse aggregate in concrete, with an aim to investigate the compressive strength and transport behavior of recycled aggregate concrete incorporating FNS as fine aggregate. 
This study includes discussion of coupled effects of FNS and recycled coarse aggregates on the resistance to water absorption and chloride penetration of concrete.

Many equations and diverse correlations between water absorption and other related durability parameters such as water permeability and rapid chloride penetration are reported by several studies. Experimental study by Zhang and Zong [15] reported that there is an exponential relation between the surface absorption of concrete and diffusion coefficient of its chloride ions. This exponential relation was found to have a correlation coefficient of the order 0.91 . Furthermore, the study determined a linear relationship between the surface absorption and permeability of the concrete. As another method to measure chloride ion transport within the concrete specimen, Classie et al. [16] used helium and mercury intrusion in their experimental study. Their study had four different concrete mixes: two concrete mixes containing SF and two control mixes without SF. A wide range of durability-related properties such as chloride transport, carbonation, oxygen transport and water vapor transport were measured, and the results of all these tests were correlated with the porosity of specimens. The study concluded that mercury intrusion method to measure porosity of cement paste and concrete is the best predictor of chloride ion transport, as mercury does not penetrate closed pores and these closed pores do not contribute to transport.

There are several standards of practice that define the water absorption of concrete and the porosity of cement paste and concrete. Each of these standards has different procedures for specimen preparation and testing that leads to different ranges of values to represent the water absorption of hardened concrete as percentage of volume. This can be misleading when describing the water absorption of a certain specific concrete mix. The various tests described by different standards of practice generally include different preconditioning procedures and limits of relevant parameters. Consequently, this results in some of the standards having a narrow range of values for the results compared to other water absorption or porosity tests. Pinto et al. [17] reported that preconditioning temperature was a significant influence factor on the results of water absorption by capillarity and by immersion. The study concluded that water absorption of concrete by immersion can increase by around $145 \%$ at low water cement ratios with the increase in the subjecting temperature $\left(105^{\circ} \mathrm{C}\right)$ during the preconditioning stage of the concrete specimen. However, it should be noted that such a high range of temperature caused substantial damage to the microstructure of concrete. The study recommended that the adoption of lower temperatures $\left(50-70{ }^{\circ} \mathrm{C}\right)$ requires more study about preconditioning time parameters.

This present study investigates water absorption as a measure of porosity of three concrete mixes with varied proportions of GGBS, SF and FA as partial replacement of OPC using four different test methods. Table 1 shows the investigated test methods and relevant standard codes or procedures used for testing.

Table 1. Investigated test methods and relevant standard test procedures followed.

Test Method

Determination of water absorption

Absorption of water by concrete by immersion

Absorption of water by concrete by immersion under vacuum

Method for Density, Absorption, and Voids in Hardened Concrete

RCP Test after 28 days of curing
Standard Codes of Tests

BS 1881: Part 122: 1983-Method for determination of water absorption RILEM CPC 11.1-RILEM Technical recommendations for the testing and use of construction materials

RILEM CPC 11.3-RILEM Technical recommendations for the testing and use of construction materials

ASTM C 642-97-Standard test method for density, absorption and voids in Hardened Concrete

ASTM C1202-19-Standard test method for electrical indication of concrete's ability to resist chloride ion penetration

In the first part of this experimental study, standard test methods for determining water absorption by concrete were carried out to determine the porosity of concrete through 
mass gain percentage or as volume of permeable pores as percentage of the solid. However, several other non-standard indicative ways to determine water absorption such as 'planar porosity', which is usually performed on concrete by obtaining thin sections from concrete specimens and later subjecting it to grinding and image processing [18], are also mentioned in the literature.

After obtaining test results of water absorption and porosity of SCM concrete mixes, the experimental investigation was extended to two more concrete mix specimens for determination of water absorption using the RILEM CPC 11.3 method. Moreover, the rapid chloride permeability test was also performed after curing the specimens for 28 days as per ASTM C1202-19. Differences between various testing methods of water absorption are identified for better understanding of concrete porosity. Water absorption values of all specimens are related to rapid chloride penetration test ratings of specimens.

\section{Experimental Program}

All the concrete mixes investigated can be classified into four groups, i.e., OPC, $\mathrm{OPC}+\mathrm{GGBS}, \mathrm{OPC}+\mathrm{GGBS}+\mathrm{MS}$, and OPC + FA + MS groups. Four concrete mixes having SCMs in varying percentages and a control mix with $(100 \%)$ OPC are investigated for determination of concrete porosity in terms of percentage of water absorption by concrete specimens. Table 2 includes details of the concrete mixes investigated in the study, the parameters determined in experimental study and the standard methods used for determination of parameters. In the first part of the study, the percentage of water absorption is determined for specimens of three concrete mixes of variable composition (OPC (100\%) OPC(50\%) + GGBS(50\%), and OPC(45\%) + GGBS(50\%) + MS(5\%)) using four standard test methods discussed earlier, as per international codes of practice (i.e., BS 1881-122, RILEM CPC 11.1, RILEM CPC 11.3, and ASTM C642).

Table 2. Experimental study details.

\begin{tabular}{|c|c|c|c|}
\hline Exp. Study & Concrete Mix & Parameters of Study & Codes and Method \\
\hline $\mathrm{I}$ & $\begin{array}{c}\text { OPC }(100 \%) \\
\text { OPC }(50 \%)+\text { GGBS(50\%) } \\
\text { OPC }(45 \%)+\text { GGBS(50\%) + MS(5\%) }\end{array}$ & Water Absorption (\%) & $\begin{array}{l}\text { BS 1881: Part 122: } 1983 \\
\text { RILEM CPC } 11.1 \\
\text { RILEM CPC } 11.3 \\
\text { ASTM C642 }\end{array}$ \\
\hline II & $\begin{array}{c}\text { OPC }(100 \%) \\
\text { OPC }(50 \%)+\text { GGBS }(50 \%) \\
\text { OPC }(45 \%)+\text { GGBS }(50 \%)+\mathrm{MS}(5 \%) \\
\text { OPC }(30 \%)+\text { GGBS }(65 \%)+\mathrm{MS}(5 \%) \\
\text { OPC }(72 \%)+\text { FA }(25 \%)+\mathrm{MS}(3 \%)\end{array}$ & $\begin{array}{c}\text { Water Absorption (\%) } \\
\text { RCP (Coulomb) at 28-day }\end{array}$ & $\begin{array}{l}\text { RILEM CPC } 11.3 \\
\text { ASTM C1202-19 }\end{array}$ \\
\hline
\end{tabular}

In the second part of the experimental program, RILEM CPC 11.3, absorption of water by concrete by immersion under vacuum is considered as the most appropriate and representative test method for determination of water absorption based on results obtained in the first part. This test is regarded as a more rigorous test on concrete specimens for determination of porosity. In this part, two additional concrete mixes incorporating different SCM (GGBS and MS with increased percentage of GGBS, and FA with MS) in varying proportions are further investigated. These additional concrete mixes are comprised of OPC $(30 \%)+$ GGBS $(65 \%)+\mathrm{MS}(5 \%)$ and OPC $(72 \%)+\mathrm{FA}(25 \%)+\mathrm{MS}(3 \%)$. All investigated concrete mixes were designed to have a compressive strength $\left(\mathrm{f}^{\prime} \mathrm{c}\right)$ equal to $40 \mathrm{Mpa}$, with a maximum aggregate size of $20 \mathrm{~mm}$. Crushed limestone aggregates and natural dune sand with a fineness modulus of 2.92 and 1.77, respectively, were used for testing purposes. The coarse aggregate used for the study had a specific gravity of 2.59 and a bulk density of $1480 \mathrm{~kg} / \mathrm{m}^{3}$, while the specific gravity of fine aggregate used for the study was found to be 2.8. Any concrete mix requires an optimum amount of water. If more water is added to cement while preparing the concrete mix, the cement particles move far from each other and the distance required for interaction and intersection of prismatic 
hydration products increases, causing larger voids between crystals and affecting the porosity values [19]. This will also reduce the concentration of cement grains throughout the medium. To avoid any such influence, a constant water/cement ratio of 0.35 for all concrete mixes along with a constant volume of total cementitious materials at $400 \mathrm{~kg} / \mathrm{m}^{3}$ was followed for the present study. Composition of concrete mixes with a proportion of ingredients is shown in Table 3. Table 4A,B contains details of the chemical composition and physical properties of ingredients used in various concrete mixes investigated.

Table 3. Composition of concrete mixes used for experimental investigation.

\begin{tabular}{|c|c|c|c|c|c|c|c|}
\hline \multirow{2}{*}{ Concrete Mix } & \multirow{2}{*}{ w/c } & \multicolumn{4}{|c|}{ Cementitious Materials $\left(\mathrm{kg} / \mathrm{m}^{3}\right)$} & \multirow{2}{*}{ Coarse Aggr. } & \multirow{2}{*}{ Fine Aggr. } \\
\hline & & OPC & GGBS & MS & FA & & \\
\hline $\mathrm{OPC}(100 \%)$ & 0.35 & 400 & - & - & - & 208 & 192 \\
\hline OPC $(50 \%)+$ GGBS( $50 \%)$ & 0.35 & 200 & 200 & - & - & 208 & 192 \\
\hline $\mathrm{OPC}(45 \%)+\mathrm{GGBS}(50 \%)+\mathrm{MS}(5 \%)$ & 0.35 & 180 & 200 & 20 & - & 208 & 192 \\
\hline $\mathrm{OPC}(30 \%)+\mathrm{GGBS}(65 \%)+\mathrm{MS}(5 \%)$ & 0.35 & 120 & 260 & 20 & - & 208 & 192 \\
\hline $\mathrm{OPC}(72 \%)+\mathrm{FA}(25 \%)+\mathrm{MS}(3 \%)$ & 0.35 & 288 & - & 12 & 100 & 208 & 192 \\
\hline
\end{tabular}

Table 4. Chemical composition and physical properties of ingredients in concrete mix.

\begin{tabular}{|c|c|c|c|c|}
\hline \multicolumn{5}{|c|}{ (A) Chemical composition of OPC, GGBS, MS and FA } \\
\hline Chemical Component & OPC (\%) & GGBS (\%) & MS (\%) & FA $(\%)$ \\
\hline Silicon dioxide $\left(\mathrm{SiO}_{2}\right)$ & 20.50 & 36.39 & 91.17 & 53.5 \\
\hline Alumina $\left(\mathrm{Al}_{2} \mathrm{O}_{3}\right)$ & 4.92 & 14.08 & 0.17 & 12.98 \\
\hline Iron oxide $\left(\mathrm{Fe}_{2} \mathrm{O}_{3}\right)$ & 3.88 & 1.08 & 0.04 & 7.03 \\
\hline Calcium oxide $(\mathrm{CaO})$ & 63.36 & 41.37 & 0.69 & 20.87 \\
\hline Sulphur trioxide $\left(\mathrm{SO}_{3}\right)$ & 2.47 & 0.45 & 0.004 & 0.67 \\
\hline Magnesium oxide (MgO) & 1.01 & 7.0 & 0.56 & 3.48 \\
\hline Sodium oxide $\left(\mathrm{Na}_{2} \mathrm{O}\right)$ & 0.54 & 0.55 & 0.58 & 1.50 \\
\hline Potassium oxide $\left(\mathrm{K}_{2} \mathrm{O}\right)$ & - & 0.36 & 2.01 & - \\
\hline Tri-calcium aluminate $\left(\mathrm{C}_{3} \mathrm{~A}\right)$ & 6.48 & - & & \\
\hline Chloride content & 0.01 & 0.02 & & 0.04 \\
\hline Loss on ignition & 2.92 & 2.4 & 1.8 & 0.11 \\
\hline Insoluble residue & 0.8 & - & & \\
\hline Moisture Content & & 0.38 & 0.55 & 0.02 \\
\hline \multicolumn{5}{|c|}{ (B) Physical properties of ingredients used in concrete mix } \\
\hline \multicolumn{5}{|l|}{ 1. Ordinary Portland cement } \\
\hline \multicolumn{4}{|c|}{ Fineness Specific Surface (m² / kg) (EN 196-6:2010) } & 342 \\
\hline \multicolumn{4}{|c|}{ Initial Setting time (min) (EN 196-3:2016) } & 140 \\
\hline \multicolumn{4}{|c|}{ Final Setting time (min) (EN 196-3:2016) } & 185 \\
\hline \multicolumn{4}{|c|}{ Soundness Le Chatelier Expansion (mm) (EN 196-3:2016) } & 1.0 \\
\hline \multicolumn{5}{|c|}{ Compressive Strength of Mortar Prism (MPa) (EN 196-1:2016) } \\
\hline \multicolumn{3}{|l|}{ 2-day } & & 24.4 \\
\hline \multicolumn{3}{|l|}{ 7-day } & & 38.7 \\
\hline \multicolumn{3}{|l|}{ 28-day } & & 52.2 \\
\hline \multicolumn{3}{|l|}{ Blaine Fineness $\left(\mathrm{m}^{2} / \mathrm{kg}\right)$} & & 342 \\
\hline
\end{tabular}


Table 4. Cont.

\begin{tabular}{llc}
\hline 2. & 50\%OPC + 50\%GGBS & 190 \\
\hline & Initial Setting time (min) & 64 \\
\hline Activity Index (\%) & 92 \\
\hline 7-day & $0.53 \%$ \\
\hline 28-day & $>110 \%$ \\
\hline Silica Fume-Oversize percent retained on a $45 \mu \mathrm{m}(324$ sieve) & $>18$ \\
\hline Accelerated pozzolanic strength activity index with OPC (7-day) & 9.8 \\
\hline Specific surface (m $\left.{ }^{2} / \mathrm{g}\right)$ & Fly Ash-Percent retained on a $45 \mu \mathrm{m}(324$ sieve) & \\
\hline
\end{tabular}

It is noteworthy that previous studies related to porosity of concrete reported that the water-to-cementitious ratio and the age of concrete affects the water absorption and porosity of hardened concrete remarkably [20]. Hence, all specimens for water absorption were tested at an age of 28 days. The porosity results indicated in this study are the average of three specimen of each concrete mix investigated.

The determination of water absorption and porosity strictly followed procedures described in respective standards of practice. However, it should be noted that the procedures described vary in preparation of specimens, testing conditions and process of testing. BS 1881: Part 122: 1983 — the test method for determination of water absorption is very common, as it is considered one of the quickest and less expensive single-point absorptivity tests [21]. It requires oven drying of concrete specimens at $105^{\circ} \mathrm{C}$ for $72 \mathrm{~h}$. After removing the specimens from the oven, they are cooled down at room temperature for $24 \mathrm{~h}$ in an airtight container, and then immediately immersed in water for $30 \mathrm{~min}$. The water absorption as per BS 1881: Part 122 is then calculated as the increase in mass gain of specimen due to immersion after the $30 \mathrm{~min}$ of water absorption as a percentage of the mass of the dry specimen. Figure 1 shows two stages of test specimens for determination of water absorption as per BS 1881: Part 122.

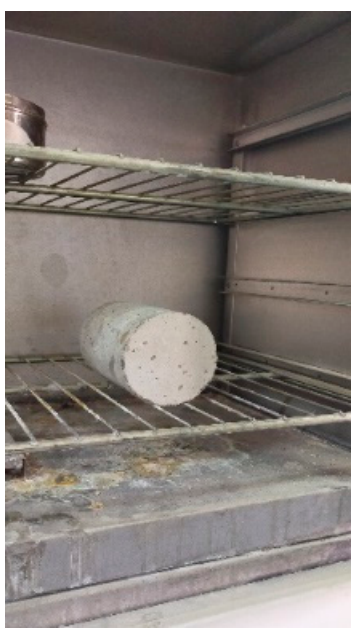

(a)

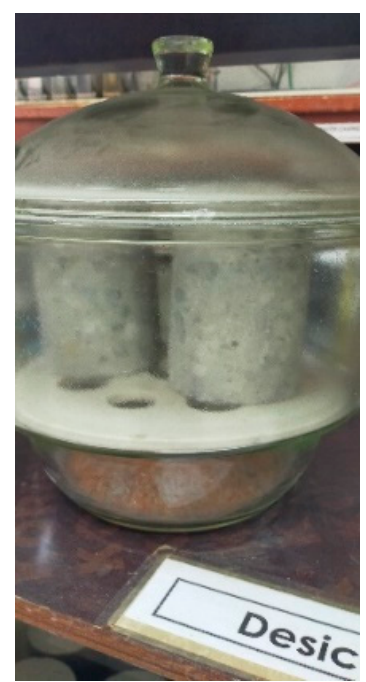

(b)

Figure 1. Test specimen for determination of water absorption as per BS 1881: Part 122: (a) oven drying of concrete specimen; and (b) cooling down of specimens in a desiccator.

RILEM CPC 11.1 requires that the specimen should be immersed in water till a constant mass of specimen is observed. The constant mass is considered when the difference between 
two measurements taken at an interval of $24 \mathrm{~h}$ is below $0.1 \%$. This constant mass of the specimens was recorded. Afterwards, oven drying of specimens at a drying temperature of $110 \pm 5{ }^{\circ} \mathrm{C}$ was conducted till a constant oven dry mass of specimens is achieved. Water absorption in this test is calculated as difference of mass between the immersed constant mass and the oven dry constant mass as percentage of the constant dry mass.

On the other hand, the RILEM CPC 11.3 test as seen in Figure 2 includes vacuuming the concrete specimens for $24 \mathrm{~h}$ after being oven dried to a constant mass as first step, and recording the corresponding mass after the specimens have cooled down to room temperature. This is followed by adding conditioning water to the vacuum while the specimens are kept there for $2 \mathrm{~h}$. Both the mass of specimens after immersion and apparent mass while the specimens are kept in the vacuum is recorded. The water absorption by concrete specimen is the difference between the mass after immersion and the oven dry mass divided by the difference between the specimen's mass after immersion and its apparent mass while it is submerged in water. This calculation is expressed as a percentage, as shown by equation (1) with $\mathrm{M}_{1}=$ oven dried mass of concrete specimen, $\mathrm{M}_{2}=$ Mass of specimen in water, and $\mathrm{M}_{3}=$ Mass in air of water-saturated specimen after vacuum.

$$
\text { Total Porosity }=\left[\frac{\mathrm{M}_{3}-\mathrm{M}_{1}}{\mathrm{M}_{3}-\mathrm{M}_{2}}\right] \times 100
$$

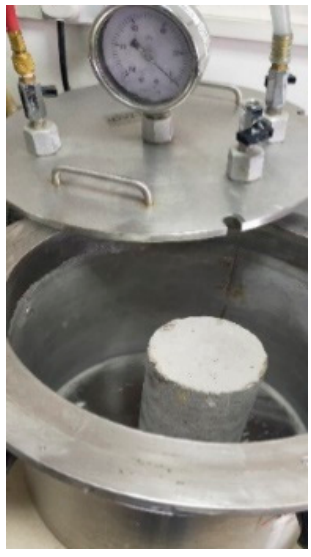

(a)

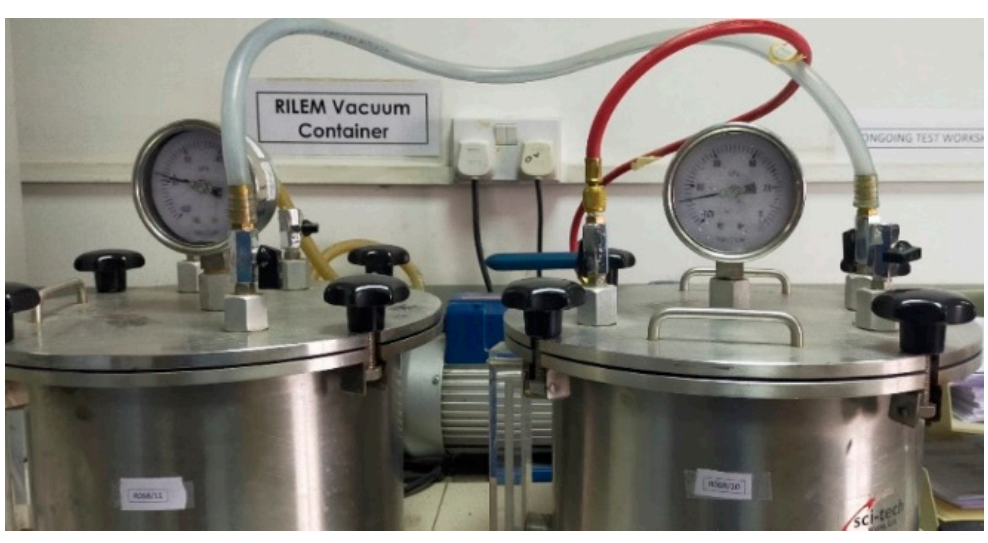

(b)

Figure 2. Vacuum conditioning with and without water as part of RILEM CPC 11.3: (a) concrete specimen in a vacuum container prior to start of test; and (b) vacuum conditioning of a concrete specimen.

$\rightarrow \quad$ This method provides a good estimate of total porosity, as it is based on the concept that the weight of an object is due to the absolute mass of a solid. In this test, the pores of the specimen are filled with a liquid medium of a known density, known as conditioning water, and hence the total effective porosity can be calculated from the change in weight.

$\rightarrow \quad$ The last water absorption test for measurement of porosity conducted in this present study conforms to ASTM C 642-97 where the specimens are oven dried at a temperature of $110.5{ }^{\circ} \mathrm{C}$ for no less than $24 \mathrm{~h}$, then immersed in the water for $48 \mathrm{~h}$. The specimens were then subjected to water boiling in metal containers and a hot plate for five hours, followed by cooling for fourteen hours by immersion in water. The mass of the specimens is recorded during each of the steps as per ASTM C642. The water absorption by concrete specimens is reported after immersion and boiling as percentage in volume of permeable pore spaces.

$\rightarrow \quad$ A Rapid Chloride Ion Penetration test in accordance with ASTM C1202-19 was also conducted on concrete specimens of all five concrete mixes. The setup of RCP tests conducted on all specimens for five concrete mixes is shown in Figure 3. The results of water absorption by concrete specimen are related to respective RCP test ratings 
for all investigated concrete mixes, OPC + GGBS concrete mixes and concrete mixes containing GGBS only. Developing this relationship between water absorption and $\mathrm{RCP}$ ratings is crucial, owing to criticisms of RCP tests.

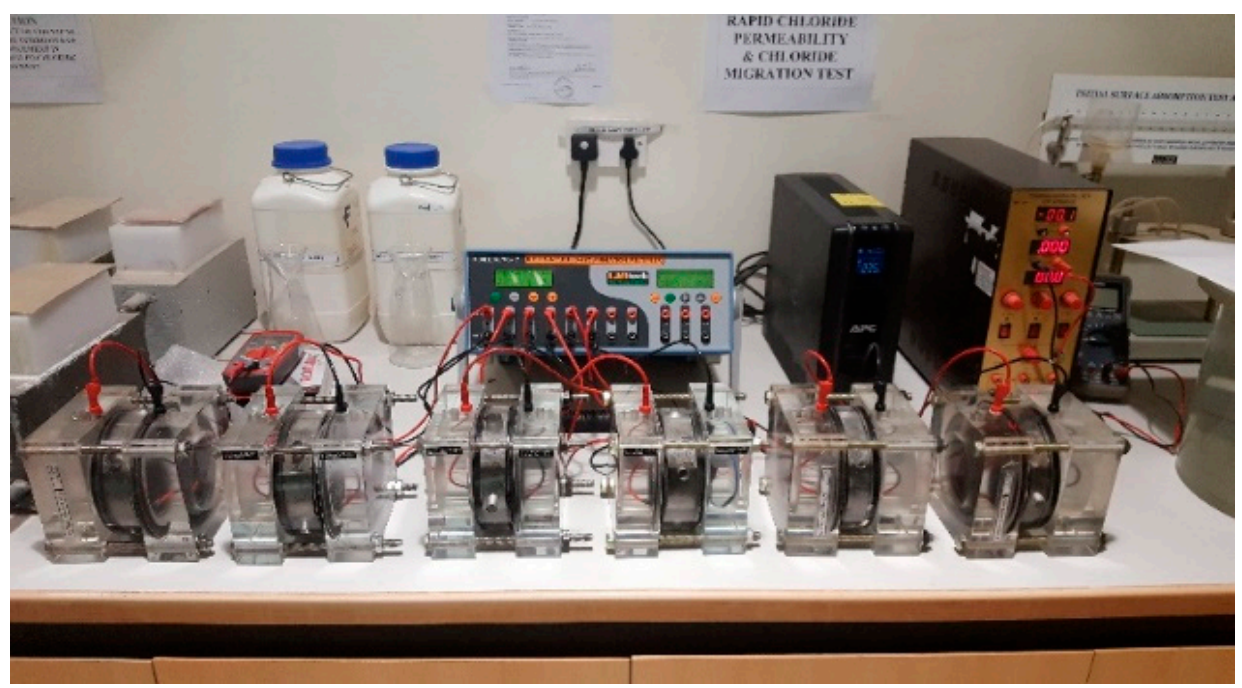

Figure 3. Rapid Chloride Ion Penetration test set up.

\section{Results and Discussion}

\subsection{Porosity of SCM Concrete Mixes by Four Standard Test Methods}

The 28-day porosity, in terms of percentage of water absorption by concrete specimens, was determined as per four standard methods described in codes of practice for three concrete mixes studied as depicted in Table 2. Figure 4 shows the average of three values for each test category and concrete mix. A disparity in range of porosity values can clearly be seen for different methods of testing for the same concrete mix. This is due to the difference in specimen preparation, conditions and testing procedures as codified in these standards. It can be seen that specimens tested using standard test methods by BS 1881-122 produced the lowest values for concrete porosity for all mixes. Further, these specimens recorded the lowest values of porosity for the triple blended mix (OPC (45\%) + GGBS( $50 \%)+\mathrm{MS}(5 \%))$ followed by the double blended mix (OPC (50\%) + GGBS(50\%)), and lastly by the single blend (control mix containing OPC $(100 \%)$ ) concrete mixture as $1.2 \%, 1.6 \%$ and $1.9 \%$, respectively. On the other hand, specimens tested using the RILEM CPC 11.3 method stated the highest values for concrete porosity compared to other test methods. They showed increased porosity values as high as 6,7 and 8.8 times porosity values obtained by the BS 1881-122 method for the single, double and triple blended concrete mixes, respectively. When the porosity of specimens was measured by the vacuum saturation method by immersing the concrete specimen under vacuum as per RILEM CPC 11.3, the specimens were completely dried until a concrete mass of specimen was obtained. Moreover, the vacuum withdraws all the remaining moisture from pores. Compared to the vacuum saturation method, BS 1881 part 122 is considered as an indirect method to determine water absorption of hardened concrete, as it measures the water content and cement content separately. This water immersion method indicates both incomplete drying for a short period of $72 \mathrm{~h}$ leading to residual water being left behind in the smaller pores in the pore system, and also due to incomplete saturation since the water can only enter the specimen by capillary absorption through the surface of the specimen. 


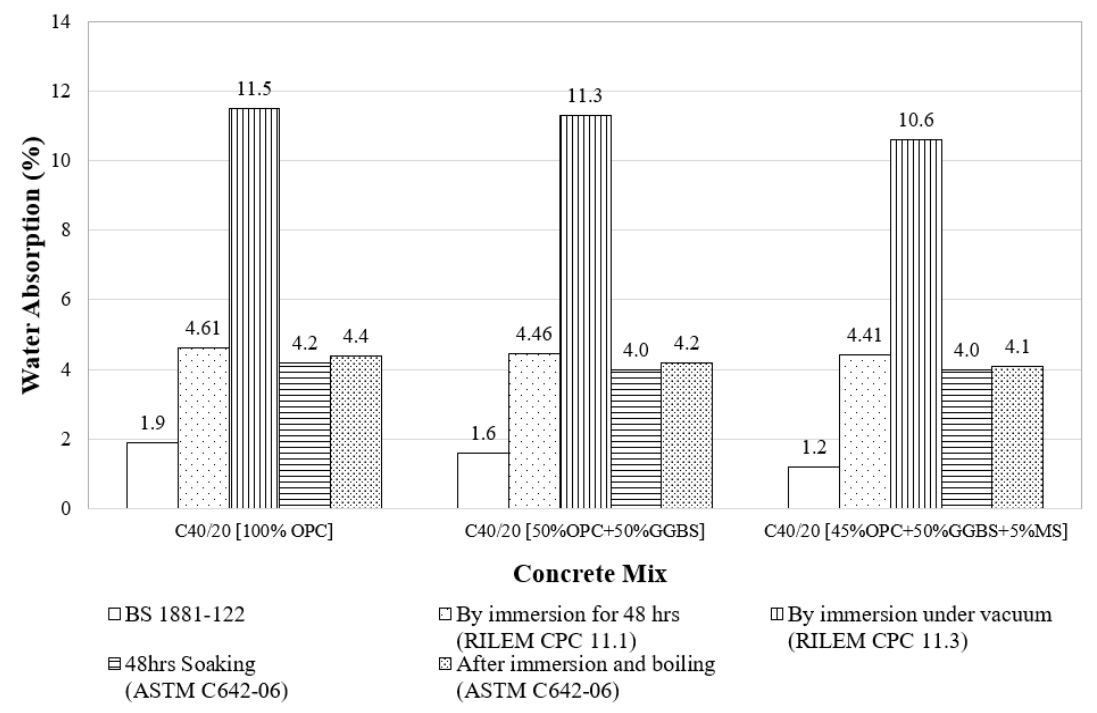

Figure 4. Porosity of concrete obtained in terms of water absorption by various test methods.

Furthermore, it can be observed that a reduction in the cement content and increase in SCM, especially for the concrete mix with MS content, resulted in a reduced porosity of concrete for all mixes investigated. It is expected that reduction in total pore volume is the result of continuous generation of pozzolanic reaction products produced by hydration of fine SCMs that fill the pores of specimens to a great extent. Concrete mixes containing MS show a further reduction of total pore volume due to high pozzolanic reactivity, infinitesimal dimensions of MS particles, and their pore filling effect. They tend to subdivide the pore space by assembling themselves between cement grains. The water-cement ratio was not observed to have a great influence on water absorption (or porosity) values for all concrete mixes investigated. Such a consistency in water absorption test results is observed irrespective of the test method used.

Moreover, Figure 4 shows concrete porosity results of specimens tested using RILEM 11.1 and ASTM C642-06 (both with and without immersion and boiling of specimens) test methods in a close vicinity. The range of porosity values for concrete mixes by these tests lie between $4.0-4.61 \%$. The ASTM C642-06 test method, including immersion and boiling steps, shows slightly higher porosity values by $0.1-0.2 \%$ compared to ones with $48 \mathrm{~h}$ of soaking only for concrete specimens of all mixes. ASTM C642-06 follows virtual saturation by using relatively small specimens that are placed in boiling water for considerable periods, while RILEM CPC No. 11.1 involves soaking the specimen until constant weight gain. In RILEM CPC No. 11.3, the oven-dried specimen is placed in a vacuum followed by immersion in water.

Due to such variation in experimental results obtained, it would be of greater interest to establish a single acceptable value of porosity for every standard test method for each concrete mix.

\subsection{Impact of SCMs on Porosity of Concrete Mix}

The impact of SCMs on the porosity of concrete mix can be understood by referring to Figure 5. It shows that incorporation of SCMs as a replacement for OPC in a concrete mix causes reduction in the water absorption or porosity of a concrete mix. This trend of reduction in porosity values with increased percentages of SCMs can be observed for all standard testing procedures followed in the present study due to the secondary hydration of supplementary cementitious materials, as they have finer particles than Portland cement. The reason for increased porosity can be attributed to incorporation of GGBS and MS in concrete mix, resulting in precipitation of additional calcium-silicate-hydrate (C-S-H) gel and calcium-aluminum-silicate-hydrate (C-S-A-H) bonds. This fills the pores between the hydrated product formed from the primary hydration of OPC. Moreover, the hydration 
of GGBS continues at a higher rate than OPC that leads to formation of C-S-H gel and consequent reduction of the permeability of concrete with time.

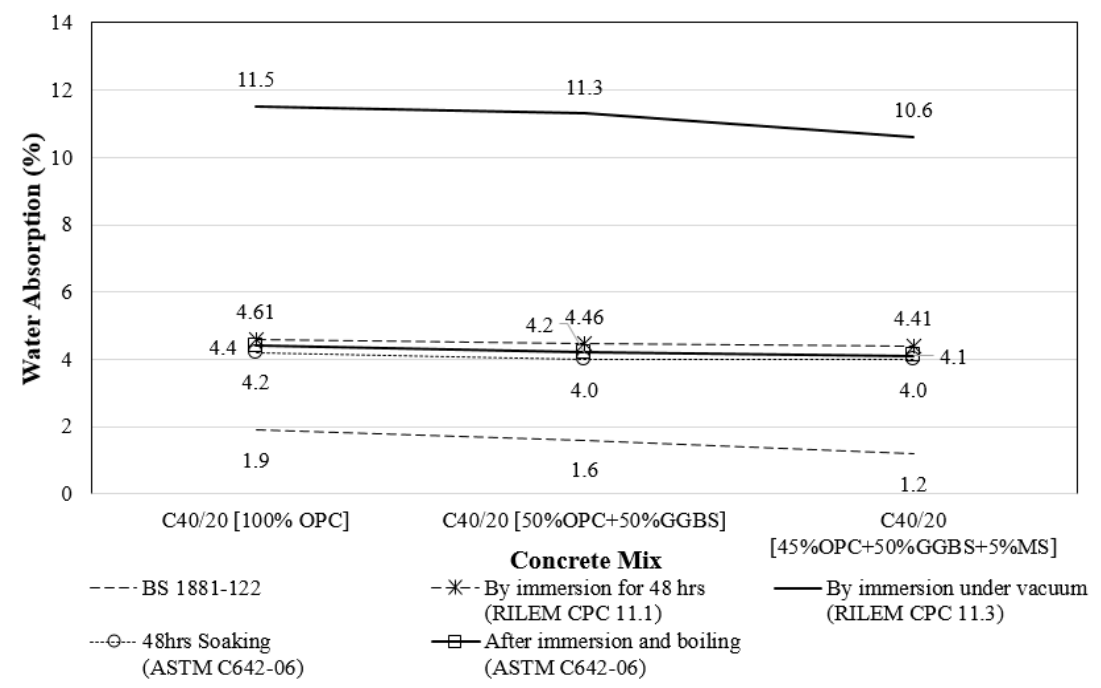

Figure 5. Impact of SCMs replacement percentages on the porosity of concrete under different standard test methods.

The reduction in porosity values by $15.79 \%$ and $36.84 \%$, respectively was observed when $50 \%$ of OPC is replaced with GGBS and when GGBS( $50 \%)+\mathrm{MS}(5 \%)$ are used as SCMs compared to a single blend concrete mix of OPC for the BS 1881-122 test method. A reduction in porosity values by $3.25 \%$ and $4.34 \%$ was seen for the RILEM CPC 11.1 test method, $1.74 \%$ and $7.83 \%$ for the RILEM CPC 11.3 test method, and $4.55 \%$ and $6.82 \%$, respectively, for the experimental study II when the ASTM C642 method with immersion and boiling of concrete specimens was used. Interestingly, the ASTM C642 test method with $48 \mathrm{~h}$ of soaking produced almost the same values of water absorption for both double and triple blended concrete mixes, representing a reduction in porosity values by $4.76 \%$ compared to the OPC concrete mix. It can also be seen from Figure 5 that higher porosity values are reported by concrete specimens tested using the RILEM CPC 11.3 method, followed by RILEM CPC 11.1, ASTM C642-06 and lastly BS 1881-122 testing methods. Moreover, concrete specimens tested using the RILEM CPC 11.3 method produced a wide variation between porosity values, implying a higher impact of incorporation of SCMs. This variation was observed to be almost $1 \%$ between single and triple blended concrete mixes.

Since concrete specimens tested using the RILEM 11.3 method produced the highest porosity values and wide variation between porosity values, such variation demands that differentiation between concrete mixes based on proportion and composition of ingredients and their impact on water absorption or porosity of hardened concrete should be thoroughly investigated. Furthermore, the selection of this test method was due its distinctive procedure of sample preparation that is considered to be stringent, in order to represent the degree of concrete porosity and water absorption by concrete.

Hence, the RILEM 11.3 testing method was selected as a representative method for further investigation on environmentally sustainable concrete mixes with higher percentages of OPC replacement and other SCMs, such as FA as depicted in Table 2. A Rapid Chloride Penetration test in accordance with ASTM C1202 was also performed on concrete specimen casts using this sustainable concrete after 28 days of curing.

\subsection{Porosity and RCP of Environmentally Sustainable Concrete}

The average 28 day porosity values in accordance with the RILEM CPC 11.3 testing method used on concrete specimens of all investigated mixes can be seen in Figure 6. Two additional concrete mixes included in this part of the study are increased by proportion of mass of GGBS (triple blended mix (OPC(30\%) + GGBS(65\%) + MS(5\%)) and another com- 
mon triple blended concrete mix containing FA and MS (OPC(72\%) + FA(25\%) + MS(3\%)) as shown in Table 2.

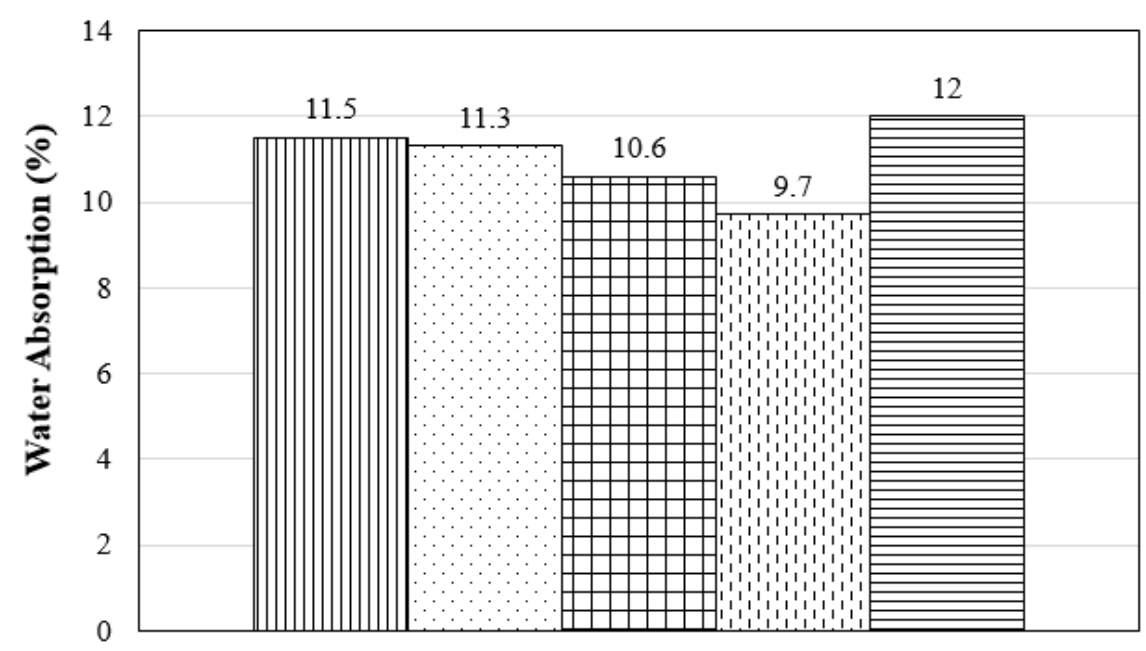

ए $40 / 20[100 \%$ OPC $]$

๑C $40 / 20[50 \% \mathrm{OPC}+50 \% \mathrm{GGBS}]$

๑ $440 / 20[45 \% \mathrm{OPC}+50 \% \mathrm{GGBS}+5 \% \mathrm{MS}]$

D $440 / 20[30 \% \mathrm{OPC}+65 \% \mathrm{GGBS}+5 \% \mathrm{MS}]$

घC $40 / 20[72 \% \mathrm{OPC}+25 \% \mathrm{FA}+3 \% \mathrm{MS}]$

Figure 6. Average 28-day porosity values as per RILEM CPC 11.3 test method for all investigated concrete mixes in study II.

Combining the previously obtained test results of porosity values as per the RILEM CPC 11.3 test method with porosity values of an additional two concrete mixes, as described, shows that an increased proportion of GGBS reduces the porosity of the concrete mix to $9.7 \%$, which is approximately a reduction of $15.7 \%$ compared to the control mix. This can be considered as a lowest porosity value of concrete specimens tested using the RILEM CPC 11.3 method for this present study. However, specimen cast using a triple blended mix containing FA and MS achieved the highest porosity values, showing water absorption of $12 \%$, as seen in Figure 6 . The addition of SCMs to concrete mix results in a less void volume of the pore structure of concrete by means of formation of C-S-H and C-A-S-H bonds, due to the reaction of pozzolan present in GGBS, MS and FA with $\mathrm{Ca}(\mathrm{OH})_{2}$ produced from hydration of OPC. This enhances the resistance of concrete to water penetration. However, sometimes higher values of water absorption and porosity of concrete are observed because these hydrated products are not formed completely, especially in cases of triple blended concrete mix where the microstructure formation of the mix is completely controlled by tertiary blending of SCMs.

\subsection{Rapid Chloride Penetration Ratings for Concrete Mixes Containing SCMs}

Figure 7 shows the average of 28 day RCP test ratings (coulombs) for concrete specimens cast using all mixes considered in this study. It can be noted that the descending order of RCP test ratings of concrete specimens for different mixes matches with water absorption or porosity test results when tests were performed using BS 1881-122, RILEM CPC 11.1, RILEM CPC 11.3, and ASTM C642 after immersion and boiling. Furthermore, the percentage reduction in RCP test values of concrete specimens compared to single blend mixes (containing 100\% OPC) is remarkably high. The percentage reduction in RCP ratings for different mixes compared to a single blend mix (control mix containing OPC $(100 \%))$ was observed to be $70.15 \%$ for the double blend, i.e., OPC $(50 \%)+$ GGBS $(50 \%)$ mix specimens, $82.15 \%$ for the triple blend OPC $(45 \%)+$ GGBS( $50 \%)+$ MS $(5 \%)$ mix specimens, $85.15 \%$ for OPC $(30 \%)+$ GGBS $(65 \%)+$ MS $(5 \%)$ mix specimens, and $64.06 \%$ for $\mathrm{OPC}(72 \%)+\mathrm{FA}(25 \%)+\mathrm{MS}(3 \%)$ mixed specimens. 


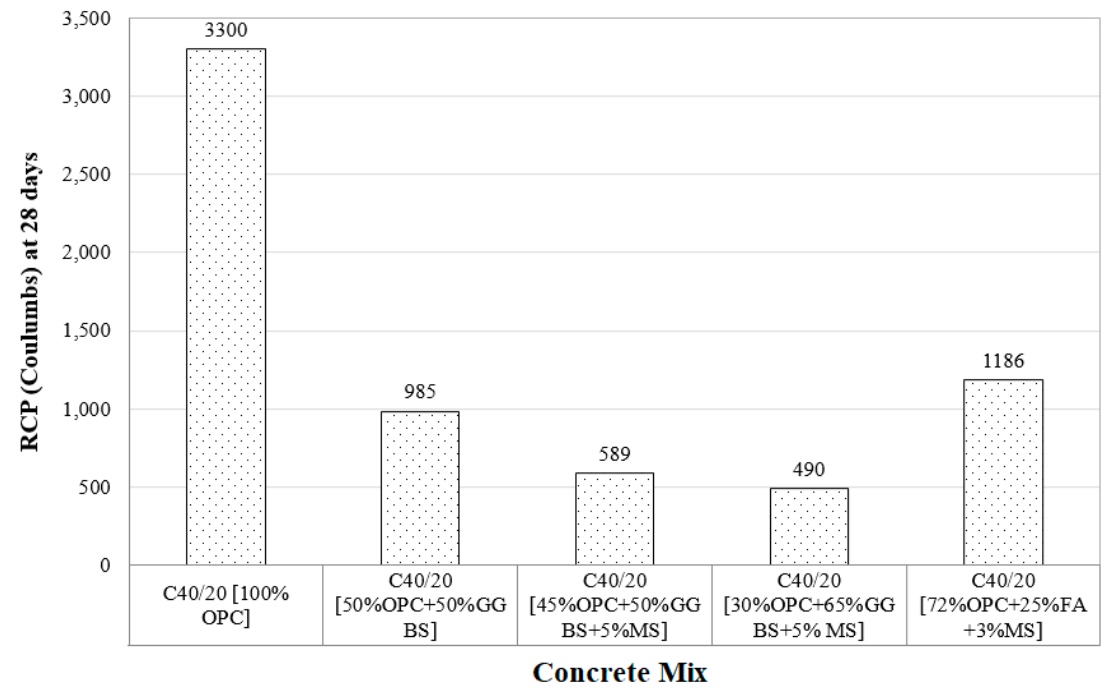

Figure 7. Average 28 day RCP result in accordance with ASTM C1202 for all investigated mixtures.

It is assumed that the chloride ion penetration resistivity is directly related to the pore network or concrete permeability, although some researchers claim that the relation is not perfect. These results show that the addition of GGBS is very effective in reducing the chloride penetrability in concrete, when compared to control mix containing $100 \%$ OPC provided sufficient hydration of GGBS is allowed to take place. It can be noticed that higher percentages of GGBS are necessary to obtain significant reductions in the chloride ingress. Even with the slower hydration of GGBS and inclusion of other SCMs such as MS, the results show that the chloride migration rating is lower for SCMs concrete than for the control mix of the same age cured as per standard procedures even at ages as early as 28 days. When SCMs are used in concrete, there is a common agreement that SCMs improve chloride ion penetration in concrete mix and thus they make concrete more resistant to the penetration of chloride ions [22]. These results indicate that the effect of the addition of GGBS in reducing the chloride ingress of concrete is able to offset the effect of the lower hydration rate and consequent higher permeability of concrete specimens at early ages, provided proper curing procedures are adopted during the early days.

The RCP test, being a standard test method, has gained a wide acceptance for quick determination of the permeability of concrete. However, over a period of time there have been many criticisms defining it as unpredictable for evaluating the durability of concrete, as this test measures the resistivity of concrete rather than permeability. In the RCP test the applied high voltage to a concrete specimen causes a temperature rise within the specimen, which can cause physical and chemical changes to the specimen. The RCP test may not represent true permeability or potential for concrete mixes that contain SCMs or chemical admixtures [23]. These objections lead to a lack of confidence in RCP tests for measuring chloride ion penetrability.

Additionally, a considerable literature of fragmented studies exists on durability of concrete (especially with respect to widely used freeze-thaw and RCP tests). There are limited research reports that encompass the evaluation of concrete mixes with a variety of SCMs, use of chemical admixtures, type of aggregates, and cement content [23-25]. Generally, concrete mixes used in infrastructure construction projects such as highway pavements and bridges contain various SCMs with low cement content and water reducing admixtures. In light of the above, a linear regression between porosity values determined using the RILEM CPC 11.3 method and RCP ratings for specimens of all mixes in the study was carried out, as seen in Figure 8. 


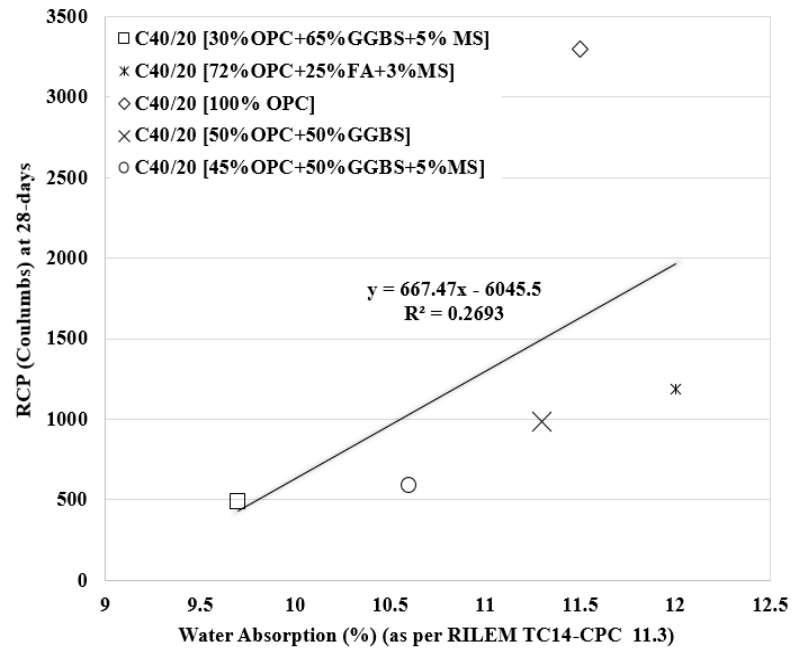

(a)

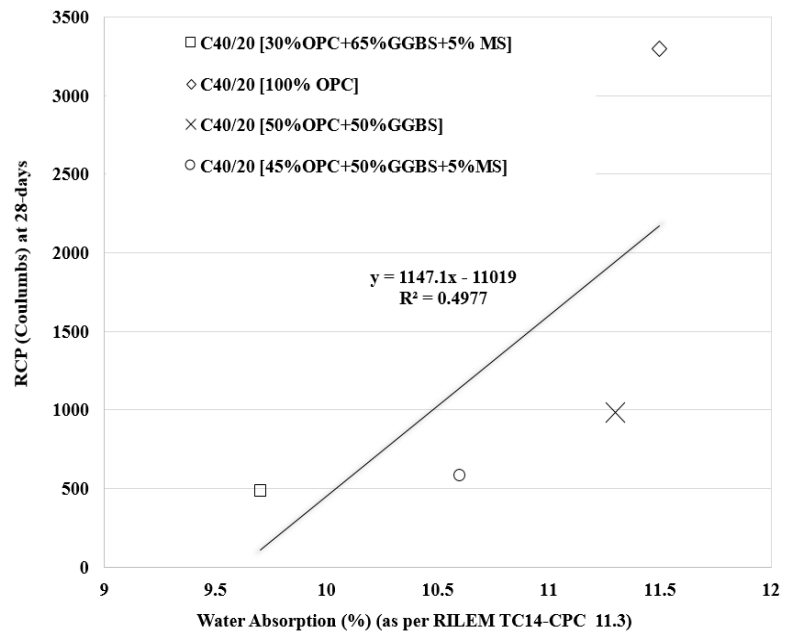

(b)

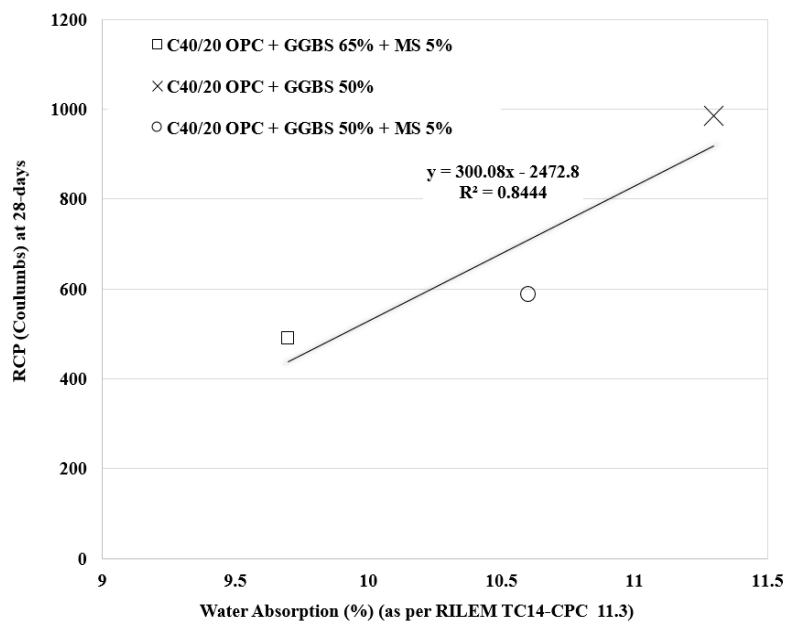

(c)

Figure 8. Linear correlation between porosity values obtained as per RILEM 11.3 and RCP ratings: (a) all investigated mixes; (b) OPC and GGBS mixes; and (c) GGBS mixtures only.

Figure 8a indicates a relatively poor goodness-of-fit for linear regression, as the coefficient of determination (R2) was found to be 0.27. Excluding the FA mixes from linear regression results in the increase of the coefficient of determination to 0.49 , as illustrated in Figure $8 \mathrm{~b}$. Although the number of investigated mixtures is low in general, the selected mixtures are very common in the market for various durability requirements, based on the environmental exposure. The concrete mix containing OPC $(100 \%)$ can be considered as a control mix to understand comparisons for durability results with other mixes containing SCMs. As linear regression analysis on specimens of all combined concrete mixes did not show satisfactory coefficients of determination between porosity and RCP ratings of mixes, concrete mixes containing GGBS only were grouped separately to find the degree of the goodness-of-fit between porosity and RCP ratings of respective specimens. Linear regression of Figure $8 \mathrm{c}$ demonstrates an acceptable coefficient of determination of the order 0.84 . Consequently, as a future scope of this present work, such a linear regression analysis between water absorption or porosity results obtained using the RILEM CPC11.3 method and RCP ratings of various other concrete mixes with varied compositions and proportions of SCMs can be carried out. A grouping between concrete mixes based on type and proportion of SCMs will be helpful in ensuring an acceptable goodness-of-fit between water absorption (or porosity) of concrete specimens and their corresponding RCP rating. This approach will prove to be an effective alternative and rapid testing method to assess chloride penetration of concrete specimens containing SCMs. 


\section{Conclusions}

Ensuring adequate durability of concrete is crucial to reduce maintenance costs and repairs for reinforced concrete structures involving SCMs, such as bridges and highway pavements. Water absorption or porosity and chloride ion penetration of concrete are key indicators for the durability assessment of concrete. In this present study, five concrete mixes with three different SCMs in varied composition and proportion are investigated for water absorption and rapid chloride penetration ratings. A comparison between porosity values obtained using four standard testing methods, i.e., BS 1881-122, RILEM CPC 11.1, RILEM CPC 11.3, and ASTM C642 are presented for three different concrete mixes. Water absorption test results showed that the mean values of water absorbed by the different concrete specimens were lower for specimens containing SCMs such as FA, MS and GGBS in comparison with ordinary concrete mixes.

It was noticed that concrete specimens tested using the RILEM CPC 11.3 method produced the highest porosity values, followed by specimens tested using RILEM CPC 11.1, ASTM C642-06 and BS 1881-122, respectively, for the same concrete mix. A wide disparity was noticed between porosity values for specimens tested using RILEM CPC 11.3 methods, indicating the impact of SCMs content; the difference in values was observed to be approximately $1 \%$ between a single and triple blended concrete mix.

The higher the GGBS or MS content in concrete mix, the lower the porosity value for all the test methods investigated. The highest percentage reduction of $15.7 \%$ compared to a single blend (control mix) was observed for specimens cast using OPC (30\%) + GGBS $(65 \%)+\mathrm{MS}(5 \%)$ concrete mix and tested by RILEM CPC 11.3 method with a water absorption value of $9.7 \%$. On the other hand, specimens cast using concrete mix containing FA developed the highest value of porosity, of the order of $12 \%$, when tested using the RILEM CPC 11.3 method.

RCP results show a significant drop in their rating (coulombs) for specimens when SCMs content increases. A more prominent drop for concrete mixes containing GGBS and MS was noticed. This drop in RCP ratings was of the order of $70.15 \%$ to $85.15 \%$ for mixes containing GGBS compared to the control mix, and a drop of $64.06 \%$ was observed for mixes containing FA.

The Rapid Chloride Ion Penetration (RCP) test is reported by many researchers to be laborious, time consuming, user dependent, and to have a high coefficient of variation. Some researchers even consider this test to be unrealistic to specify any performance-based specifications. Hence, the results of water absorption or porosity values obtained by the RILEM CPC 11.3 method are correlated with RCP ratings of concrete specimens in this present study as an effective alternative and rapid approach to assess chloride penetration of concrete specimens containing SCMs. An acceptable coefficient of determination is obtained for linear regression between RCP ratings and porosity values of concrete specimens including GGBS.

Author Contributions: Conceptualization, M.K.; methodology, M.K.; formal analysis, M.K.; investigation, A.K.; resources, M.K.; data curation, M.K. and A.K.; writing—original draft preparation, M.K. and A.K.; writing — review and editing, M.K.; supervision, M.K. All authors have read and agreed to the published version of the manuscript.

Funding: This research was funded by The Office of Research and Sponsored Programs-Abu Dhabi University under Faculty Research Incentive Grant.

Institutional Review Board Statement: Not applicable.

Informed Consent Statement: Informed consent was obtained from all subjects involved in the study.

Data Availability Statement: Not applicable.

Conflicts of Interest: The authors declare that there is no conflict of interest regarding the publication of this paper. 


\section{References}

1. Khartabil, A.; Martini, S.A. Thermal Transmission Properties of Sustainable Concrete with Supplementary Cementitious Materials. Key Eng. Mater. 2020, 853, 142-149. [CrossRef]

2. Al Martini, S.; Khartabil, A. Bulk Electrical Conductivity to Assess Chloride Penetration in Reinforced Concrete Bridges. In Proceedings of the 10th International Conference on Short and Medium Span Bridges, Quebec City, QC, Canada, 31 July-3 August 2018.

3. Saraswathy, V.; Song, H.W. Evaluation of Cementitious Repair Mortars for Corrosion Resistance. Port. Electrochim. 2008, 26, 417-432. [CrossRef]

4. Dean, S.; Montes, F.; Valavala, S.; Haselbach, L.M. A New Test Method for Porosity Measurements of Portland Cement Pervious Concrete. J. ASTM Int. 2005, 2, 1-13. [CrossRef]

5. Malecot, Y.; Zingg, L.; Briffaut, M.; Baroth, J. Influence of free water on concrete triaxial behavior: The effect of porosity. Cem. Concr. Res. 2019, 120, 207-216. [CrossRef]

6. Accary, A.; Malecot, Y.; Daudeville, L. Design and Evaluation of a Deformable Sensor for Interstitial Pore Pressure Measurement in Concrete under Very High Stress Level. Appl. Sci. 2019, 9, 2610. [CrossRef]

7. Baroth, J.; Briffaut, M.; Vu, D.; Malecot, Y.; Daudeville, L. Prediction of perforation into concrete accounting for saturation ratio influence at high confinement. Int. Jr. Impact Eng. 2021, 156, 103293. [CrossRef]

8. Khalaf, F.M.; DeVenny, A.S. New Tests for Porosity and Water Absorption of Fired Clay Bricks. J. Mater. Civ. Eng. 2002, 14, 334-337. [CrossRef]

9. Khartabil, A.; Al Martini, S. Carbonation Resistance of Sustainable Concrete Using Recycled Aggregate and Supplementary Cementitious Materials. Key Eng. Mater. 2019, 803, 246-252. [CrossRef]

10. Ding, S.; Liang, X.; Zhang, Y.; Fang, Y.; Zhou, J.; Kang, T. Capillary Water Absorption and Micro Pore Connectivity of Concrete with Fractal Analysis. Crystals 2020, 10, 892. [CrossRef]

11. Zhuang, S.; Wang, Q. Inhibition mechanisms of steel slag on the early-age hydration of cement. Cem. Concr. Res. 2021, 140, 106283. [CrossRef]

12. Chen, Q.; Ma, R.; Li, H.; Jiang, Z.; Zhu, H.; Yan, Z. Effect of chloride attack on the bonded concrete system repaired by UHPC. Constr. Build. Mater. 2021, 272, 121971. [CrossRef]

13. Wang, D.; Wang, Q.; Huang, Z. Reuse of copper slag as a supplementary cementitious material: Reactivity and safety. Resour. Conserv. Recycl. 2020, 162, 105037. [CrossRef]

14. Bao, J.; Yu, Z.; Wang, L.; Zhang, P.; Wan, X.; Gao, S.; Zhao, T. Application of ferronickel slag as fine aggregate in recycled aggregate concrete and the effects on transport properties. J. Clean. Prod. 2021, 304, 127149. [CrossRef]

15. Zhang, S.P.; Zong, L. Evaluation of relationship between water absorption and durability of concrete materials. Adv. Mater. Sci. Eng. 2014, 14, 1-8. [CrossRef]

16. Claisse, P.A.; Cabrera, J.G.; Hunt, D.N. Measurement of porosity as a predictor of the durability performance of concrete with and without condensed silica fume. Adv. Cem. Res. 2001, 3, 165-174. [CrossRef]

17. Pinto, S.R.; Macedo, A.L.A.; Medeiros Junior, R.A. Effect of preconditioning temperature on the water absorption of concrete. J. Build. Pathol. Rehabil. 2018, 3, 1-10. [CrossRef]

18. Liu, R.; Liu, H.; Sha, F.; Yang, H.; Zhang, Q.; Shi, S.; Zheng, Z. Investigation of the porosity distribution permeability and mechanical performance of pervious concretes. Processes 2018, 6, 78. [CrossRef]

19. Neville, A.M.; Brooks, J.J. Concrete Technology; Pearson Education Limited: London, UK, 2010; Volume 12.

20. Li, Y.; Dong, W.; Li, H.; Li, W. Method of vacuum water absorption to determine the porosity of hardened concrete. Int. J. Struct. Civ. Eng. Res. 2015, 4, 282-286. [CrossRef]

21. Concrete Institute of Australia. Concrete Durability Series Z7/07: Performance Tests to Assess Concrete Durability; Engineers Media: North Sydney, Australia, 2015.

22. Cantero, B.; Bravo, M.; deBrito, J.; Sáez del Bosque, I.F.; Medina, C. Assessment of the Permeability to Aggressive Agents of Concrete with Recycled Cement and Mixed Recycled Aggregate. Appl. Sci. 2021, 11, 3856. [CrossRef]

23. Sakir, S.; Raman, S.N.; Safiuddin, M.; Kaish, A.B.M.A.; Mutalib, A.A. Utilization of by-products and wastes as supplementary Cementitious Materials in Structural Mortar for Sustainable Construction. Sustainability 2020, 12, 3888. [CrossRef]

24. Joshi, P.; Chan, C. Rapid chloride permeability testing. Concr. Constr. 2002, 47, 37-43.

25. Moini, M.; Sobolev, K.; Flores-Vivian, I.; Muzenski, S.; Pham, L.T.; Cramer, S.; Beyene, M. Durability of Concrete Mixtures Containing Supplementary Cementitious Materials in Rapid Chloride Permeability Test. ACI Mater. J. 2019, 115, 67-76. [CrossRef] 